\title{
Endoscopic Band Ligation Versus Argon Plasma Coagulation in the Treatment of Gastric Antral Vascular Ectasia: A Systematic Review and Meta-Analysis of Randomized Controlled Trials
}

\author{
Bruno Salomão Hirsch', Igor Braga Ribeiro', Mateus Pereira Funari', Diogo Turiani Hourneaux de Moura', Sergio Eiji Matuguma', \\ Sergio A. Sánchez-Luna ${ }^{2,3}$, Fabio Catache Mancini', Guilherme Henrique Peixoto de Oliveira', Wanderley Marques Bernardo ${ }^{1}$ and \\ Eduardo Guimarães Hourneaux de Moura' \\ ${ }^{1}$ Gastrointestinal Endoscopy Unit, Hospital das Clínicas, University of Sao Paulo School of Medicine, São Paulo, Brazil, ${ }^{2}$ Center for \\ Advanced Endoscopy, Division of Gastroenterology, Hepatology, and Nutrition, Allegheny Health Network, Pittsburgh, Pennsylvania, \\ ${ }^{3}$ Basil I. Hirschowitz Endoscopic Center of Excellence, Division of Gastroenterology and Hepatology, Department of Internal Medicine, \\ The University of Alabama at Birmingham, Birmingham, Alabama, USA.
}

Background/Aims: Argon plasma coagulation (APC) is the most commonly used endoscopic treatment for gastric antral vascular ectasia (GAVE). Endoscopic band ligation (EBL) has emerged as an alternative therapy. Our goal was to evaluate the feasibility, efficacy, and safety of APC and EBL for the treatment of GAVE. This is the first systematic review that included only randomized controlled trials (RCTs) on this topic.

Methods: A comprehensive search was performed using electronic databases to identify RCTs comparing APC and EBL for the treatment of GAVE following the Preferred Reporting Items for Systematic Reviews and Meta-analyses guidelines.

Results: Four RCTs were included, with a total of 204 patients. EBL was related to higher endoscopic eradication rates risk difference [RD], 0.29; 95\% confidence interval [CI] [0.14, 0.44]; $\left.I^{2}=0 \%\right)$ and less bleeding recurrence than APC (RD, 0.29; 95\% CI [0.15, 0.44]; $I^{2}=0 \%$ ). Patients treated with EBL required fewer blood transfusions (mean difference [MD], 1.49; 95\% CI [0.28, 2.71]; $\left.I^{2}=96 \%\right)$ and hospitalizations (MD, $0.29 ; 95 \%$ CI $[0.19,0.39] ; I^{2}=0 \%$ ). The number of sessions required for the obliteration of lesions was higher with APC. There was no difference in the incidence of adverse events.

Conclusions: EBL is superior to APC in the treatment of GAVE in terms of endoscopic eradication rates, recurrence of bleeding, and transfusion requirements. Clin Endosc 2021;54:669-677

Key Words: Argon plasma coagulation; Endoscopic band ligation; Endoscopy; Gastric antral vascular ectasia

\section{INTRODUCTION}

Gastric antral vascular ectasia (GAVE) is a condition characterized by vascular lesions usually located in the antrum,

\footnotetext{
Received: January 30, 2021 Revised: March 27, 2021

Accepted: March 28, 2021

Correspondence: Igor Braga Ribeiro

Gastrointestinal Endoscopy Unit, Hospital das Clínicas, University of Sao Paulo School of Medicine, Av. Dr Enéas de Carvalho Aguiar, 225, 6o andar, bloco 3, Cerqueira Cesar, São Paulo 05403-010, Brazil

Tel: +55-92-98137-7788, Fax: +55-11-2661-6467, E-mail: igorbraga1@gmail.com ORCID: https://orcid.org/0000-0003-1844-8973
}

(c) This is an Open Access article distributed under the terms of the Creative Commons Attribution Non-Commercial License (http://creativecommons.org/ licenses/by-nc/3.0) which permits unrestricted non-commercial use, distribution, and reproduction in any medium, provided the original work is properly cited. typically leading to occult or overt bleeding. It accounts for up to $4 \%$ of all non-variceal upper gastrointestinal bleeding and can be present in $6-14 \%$ of patients with cirrhosis. ${ }^{1,2}$ Patients commonly present with chronic iron deficiency anemia, and up to $62 \%$ of patients can become transfusion-dependent. ${ }^{3}$ Diagnosis is usually established using esophagogastroduodenoscopy (EGD); however, ambiguous cases require histologic assessment. ${ }^{4-6}$ Endoscopically, it may present with three different patterns: stripes radiating to the pylorus (classically called "watermelon stomach," more common in non-cirrhotic patients), diffuse punctate lesions (more common in cirrhotic patients), and a nodular type.,

Pharmacological therapies have been shown to have limited benefit. $^{9-12}$ Antrectomy has a higher morbidity and mortality. ${ }^{5}$ 
Transjugular intrahepatic portosystemic shunt is also not an effective therapy. ${ }^{13}$ Therefore, similar to several causes of upper gastrointestinal bleeding, ${ }^{14-18}$ the mainstay treatment of GAVE is endoscopic therapy.

Argon plasma coagulation (APC) is a non-contact technique that delivers high-frequency monopolar current through ionized argon gas, resulting in tissue coagulation with limited depth of injury and lower risk of complications. ${ }^{19-21}$ Endoscopic band ligation (EBL), first described as a treatment for esophageal varices, was further introduced as a treatment for GAVE. It consists of mechanical strangulation of lesions through the placement of multiple elastic bands, resulting in thrombosis, necrosis, and subsequent fibrosis of the mucosa and submucosa. 22,23 Heater probes, Nd-YAG lasers, sclerotherapy, and cryotherapy have been largely replaced because of complications, lower success rates, and/or availability issues. ${ }^{5,24}$ More recently, radiofrequency ablation (RFA) and hybrid-APC have emerged as alternative therapies. ${ }^{25-27}$

Despite considerable recurrence rates ${ }^{28} \mathrm{APC}$ remains the most commonly used endoscopic treatment for GAVE, although EBL has produced promising results. We performed the first systematic review and meta-analysis including only randomized controlled trials comparing both treatment modalities. We aimed to evaluate the feasibility, efficacy, and safety of APC and EBL for the treatment of GAVE.

\section{MATERIALS AND METHODS}

\section{Protocol and registration}

This study was performed in conformity with the Preferred Reporting Items for Systematic Reviews and Meta-analyses (PRISMA) guidelines ${ }^{29}$ and was registered in the International Prospective Register of Systematic Reviews (PROSPERO) under the file number CRD42020191896. The study was approved by the Ethics Committee of the Hospital das Clínicas, Faculty of Medicine at the University of São Paulo.

\section{Eligibility criteria}

We screened all studies with the following inclusion criteria: a. Study design: only randomized controlled trials.

b. Population: patients with GAVE, irrespective of age.

Table 1. Baseline Characteristics of the Population and Results of Individual Studies

\begin{tabular}{|c|c|c|c|c|c|c|c|c|}
\hline & \multicolumn{2}{|c|}{ Abdelhalim (2014) } & \multicolumn{2}{|c|}{ Elhendawy (2015) } & \multicolumn{2}{|c|}{ Ghobrial (2018) } & \multicolumn{2}{|c|}{ Al-Wahab (2019) } \\
\hline & EBL & APC & EBL & APC & EBL & APC & EBL & APC \\
\hline Number of patients & 20 & 20 & 44 & 44 & 20 & 20 & 18 & 18 \\
\hline Mean age (years) & 55.65 & 57.17 & 51.41 & 53.09 & 9.65 & 7.8 & 65 & 60 \\
\hline Bleeding (occult/overt) & $20 \% / 80 \%$ & $45 \% / 55 \%$ & NI & NI & $0 \% / 100 \%$ & $0 \% / 100 \%$ & $17 \% / 83 \%$ & $23 \% / 77 \%$ \\
\hline Gender (male/female) & $9 / 11$ & $10 / 10$ & $19 / 25$ & $15 / 29$ & $13 / 7$ & $11 / 9$ & $11 / 7$ & $15 / 3$ \\
\hline APC settings & - & $\begin{array}{c}60 \mathrm{~W} \\
2 \mathrm{~L} / \mathrm{min}\end{array}$ & - & $\begin{array}{c}60 \mathrm{~W} \\
2 \mathrm{~L} / \mathrm{min}\end{array}$ & - & $\begin{array}{c}40 \mathrm{~W} \\
1 \mathrm{~L} / \mathrm{min}\end{array}$ & - & $\begin{array}{c}50 \mathrm{~W} \\
2 \mathrm{~L} / \mathrm{min}\end{array}$ \\
\hline Number of bands & $\begin{array}{l}\text { Up to } 18 \\
\text { bands }\end{array}$ & - & $\begin{array}{l}\text { Up to } 12 \\
\text { bands }\end{array}$ & - & $\begin{array}{l}\text { Up to } 6 \\
\text { bands }\end{array}$ & - & NI & - \\
\hline Number of sessions required & $2.25 \pm 0.64$ & $5.5 \pm 3.76$ & $2.93 \pm 0.85$ & $3.48 \pm 0.90$ & $1.85 \pm 0.18$ & $4.15 \pm 1.22$ & $2.25 \pm 0.38$ & $2.5 \pm 0.57$ \\
\hline Procedure time (minutes) & NI & NI & NI & NI & $9.4 \pm 1.21$ & $15.37 \pm 1.56$ & NI & NI \\
\hline Recurrence of bleeding & $1 / 20$ & $7 / 20$ & $\mathrm{NI}$ & NI & $1 / 20$ & $7 / 20$ & $3 / 18$ & $8 / 18$ \\
\hline Endoscopic eradication & $19 / 20$ & $12 / 20$ & NI & NI & $19 / 20$ & $12 / 20$ & $13 / 18$ & $10 / 18$ \\
\hline $\begin{array}{l}\text { Hb level after intervention } \\
(\mathrm{g} / \mathrm{dL})\end{array}$ & $9.68 \pm 1.31$ & $8.92 \pm 2.12$ & $10.31 \pm 1.01$ & $9.85 \pm 0.91$ & $9.2 \pm 0.84$ & $9.02 \pm 1.32$ & $8.8 \pm 1.0$ & $8.7 \pm 0.9$ \\
\hline $\begin{array}{l}\text { Mean number of hospital- } \\
\text { izations }\end{array}$ & $0.05 \pm 0.22$ & $0.5 \pm 0.95$ & NI & NI & $0.67 \pm 0.15$ & $0.95 \pm 0.18$ & NI & $\mathrm{NI}$ \\
\hline $\begin{array}{l}\text { Transfusion requirements } \\
\text { (units) }\end{array}$ & $0.15 \pm 0.67$ & $2.00 \pm 2.97$ & $2.5 \pm 0.70$ & $4.6 \pm 0.89$ & $0.44 \pm 0.1$ & $1.0 \pm 0.67$ & $\mathrm{NI}$ & $\mathrm{NI}$ \\
\hline $\begin{array}{l}\text { Transfusion requirements } \\
\text { (number of patients) }\end{array}$ & $\mathrm{NI}$ & $\mathrm{NI}$ & $\begin{array}{c}2 \\
(4.5 \%)\end{array}$ & $\begin{array}{c}5 \\
(11.4 \%)\end{array}$ & $\mathrm{NI}$ & NI & $\begin{array}{c}3 \\
(17 \%)\end{array}$ & $\begin{array}{c}7 \\
(39 \%)\end{array}$ \\
\hline $\begin{array}{l}\text { Adverse events (number of } \\
\text { patients) }\end{array}$ & $0 / 20(0 \%)$ & $0 / 20(0 \%)$ & $6 / 44(13 \%)$ & $9 / 44(20 \%)$ & $14 / 20(70 \%)$ & $2 / 20(10 \%)$ & $6 / 18(33 \%)$ & $0 / 18(0 \%)$ \\
\hline
\end{tabular}

APC, argon plasma coagulation; EBL, endoscopic band ligation; Hb, hemoglobin; L, liters; NI, not informed; W, watts. 
c. Type of intervention: APC and EBL.

d. Outcomes: endoscopic eradication, recurrence of bleeding, blood transfusion requirements, number of sessions needed, number of hospitalizations, and adverse events.

\section{Search and study selection}

We searched electronic databases (MEDLINE, Embase, Cochrane Library, LILACS) and gray literature from inception to March 2021. Only randomized controlled trials (RCTs) comparing APC and EBL for the treatment of GAVE were included. No restrictions were set for the publication date or language. The search strategies are listed in Supplementary Table 1. Two independent investigators screened for eligibility. Any disagreements were resolved by consultation with a third reviewer.

\section{Data collection process}

The following data were extracted: name and year of the study, number of patients, age, gender, type of bleeding (occult or overt), argon plasma settings, number of bands, ChildPugh score, number of sessions, procedure time, recurrence of bleeding, endoscopic eradication, hemoglobin level after the intervention, number of hospitalizations, transfusion requirements, and adverse events. When insufficient data were presented in the published articles, the corresponding authors were consulted via e-mail for further elucidation.

\section{Risk of bias and quality of studies}

The risk of bias was assessed using the Cochrane risk-ofbias tool for randomized trials (RoB2) ${ }^{30}$ We analyzed the risk of bias for each outcome in all included studies. The quality of evidence was assessed using the Grading of Recommendations Assessment, Development, and Evaluation (GRADE) criteria using GRADEpro Guideline Development Tool software (Mc Master University, Ontario, Canada). Egger's test was performed to assess potential publication bias.

\section{Data synthesis and statistical analysis}

The sample mean was estimated, when needed, from its median and range. ${ }^{31}$ Statistical analyses were conducted using the RevMan software Version 5.4 (Cochrane, London, UK). The Mantel-Haenszel test was used for categorical variables, and inverse variance was used for continuous variables. Heterogeneity was evaluated using the Higgins test $\left(I^{2}\right) . I^{2}$ values $>50 \%$ were considered to indicate substantial heterogeneity. ${ }^{30} \mathrm{We}$ used a fixed effects model when $I^{2}$ was $<50 \%$. If $I^{2}>50 \%$, we performed a sensitivity analysis using a funnel plot to identify possible outliers. If the sample became homogeneous after excluding possible outliers, the studies were permanently excluded (considered true outliers), and a fixed effects model was used. When there were no outliers or heterogeneity remained high after outliers were excluded, we used random effects to reduce the influence of heterogeneity on the final result. Outcome measures are described as the mean difference or risk difference (RD), with their corresponding 95\% confidence intervals (CI). Intention-to-treat analysis was performed in all studies.

\section{RESULTS}

\section{Literature search results and characteristics of included studies}

The search strategy identified 5,587 articles. After removing duplicates, 1,478 articles were identified. Among these, 11 were eligible for full-text review. Five observational studies, ${ }^{22,32-35}$ one review, ${ }^{5}$ and one study ${ }^{36}$ with duplicate data were excluded. A total of four randomized controlled trials ${ }^{37-40}$ met the inclusion criteria, including a total of 204 patients, comparing EBL with APC (102 patients in each group) (Fig. 1). The baseline characteristics of the population and the results of the individual studies are presented in Table 1 . All included studies had a follow-up period of 6 months.

\section{Risk of bias and quality of studies}

The overall risk of bias is shown in Supplementary Table 2. One ${ }^{40}$ of the four studies ${ }^{37-40}$ described "alternatively randomization" without specifying how it was performed. After contacting the author, randomization was judged to have been performed appropriately. For this reason, we considered the overall risk of bias to be insignificant. The quality of the included studies was considered to be adequate (Supplementary Table 3). Egger's test revealed no evidence of publication bias among the studies $(p>0.05)$.

\section{Meta-analysis}

\section{Endoscopic eradication}

In total, 116 patients from three studies were analyzed. ${ }^{37,39,40}$ EBL had a higher endoscopic eradication rate than that of $\operatorname{APC}\left(\mathrm{RD}, 0.29 ; 95 \% \mathrm{CI}[0.14,0.44] ; p=0.0001 ; I^{2}=0 \%\right.$ ) (Fig. 2). The GRADE analysis revealed a high certainty of evidence.

\section{Recurrence of bleeding}

In total, 116 patients from three studies were analyzed. ${ }^{37,39,40}$ EBL presented less recurrence of bleeding than that of the APC group (RD, 0.29; 95\% CI $[0.15,0.44] ; p<0.0001 ; I^{2}=0 \%$ ) (Fig. 3). The GRADE analysis revealed a high certainty of evidence. 

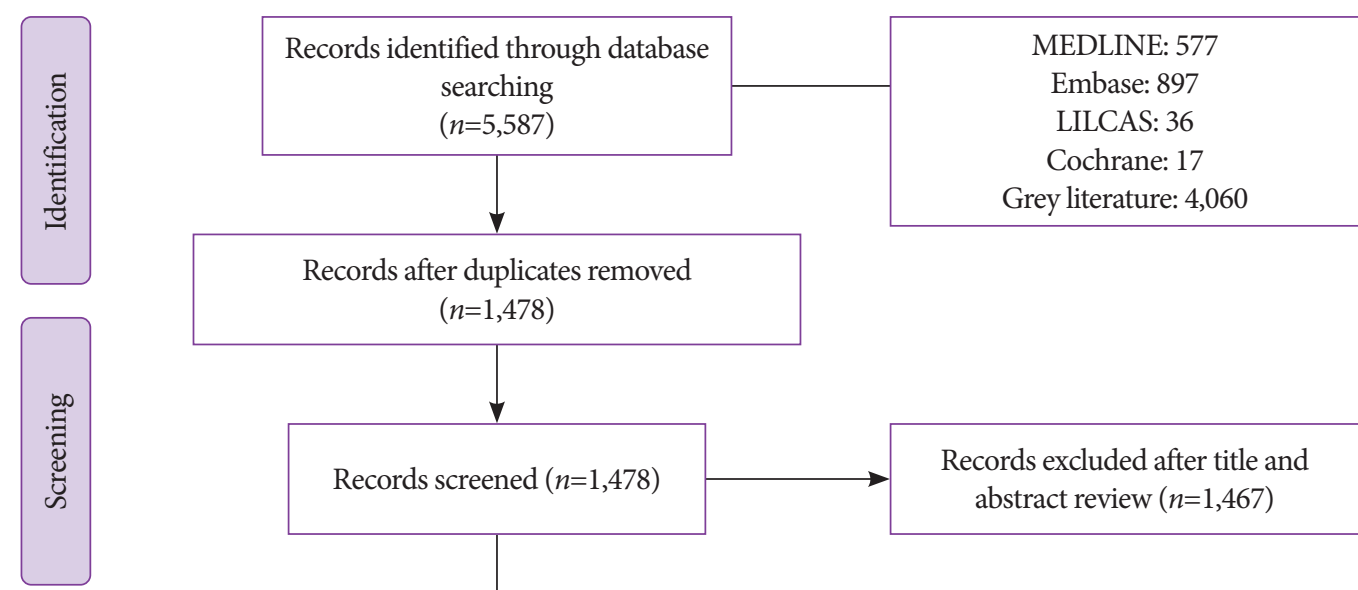

Records after duplicates removed $(n=1,478)$
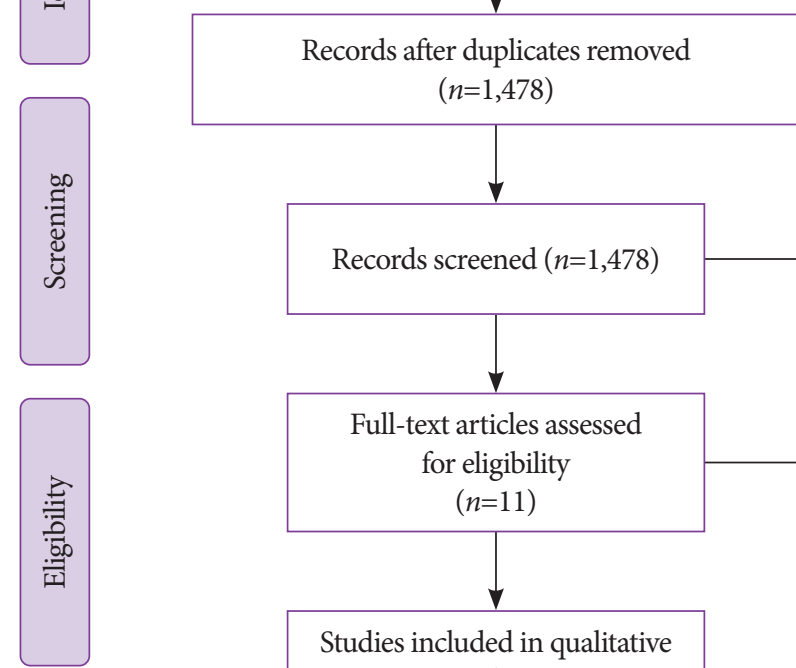

Grey literature: 4,060

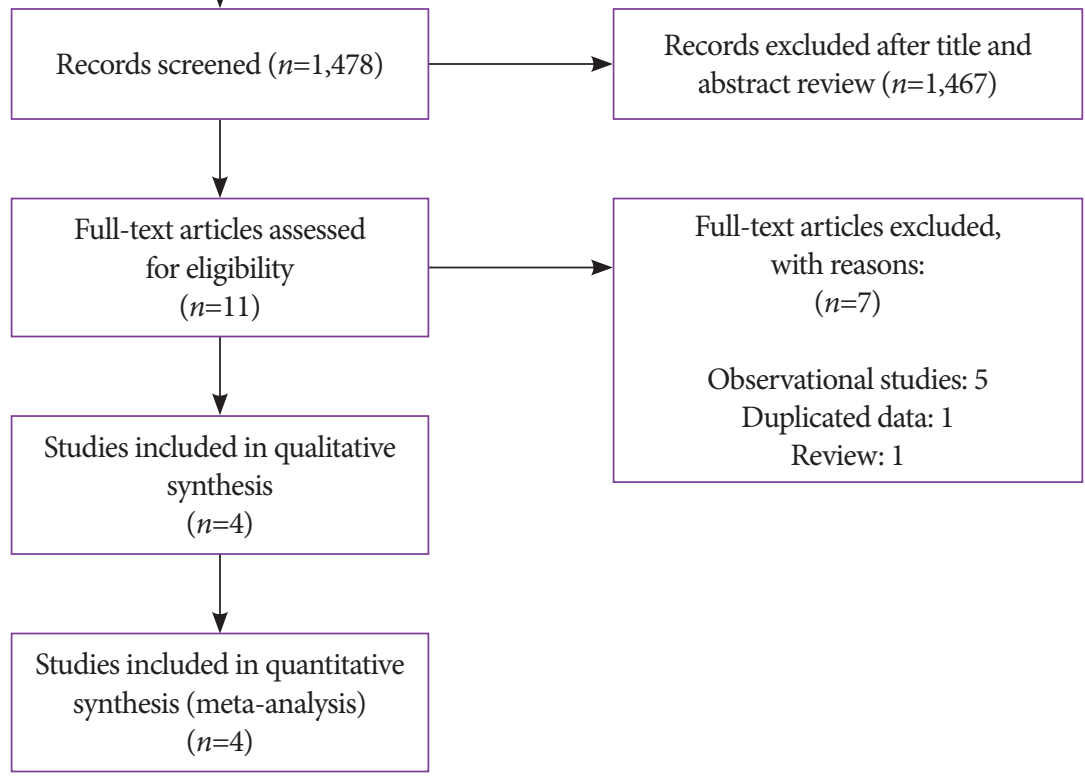

Fig. 1. Preferred Reporting Items for Systematic Reviews and Meta-analyses PRISMA flow diagram.

\begin{tabular}{lccccc} 
& \multicolumn{2}{c}{ APC } & \multicolumn{2}{c}{ EBL } \\
Study or Subgroup & Events & Total & Events & Total & Weight \\
\hline Abd AI-Wahab 2019 & 10 & 18 & 13 & 18 & $31.0 \%$ \\
Abdelhalim 2014 & 12 & 20 & 19 & 20 & $34.5 \%$ \\
Ghobrial 2018 & 12 & 20 & 19 & 20 & $34.5 \%$ \\
& & & & & \\
Total (95\% Cl) & & 58 & & 58 & $100.0 \%$ \\
Total events & 34 & 51 & & \\
Heterogeneity: Chi $^{2}=1.09, \mathrm{df}=2(p=0.58) ; I^{2}=0 \%$ \\
Test for overall effect: $\mathrm{Z}=3.84(p=0.0001)$
\end{tabular}

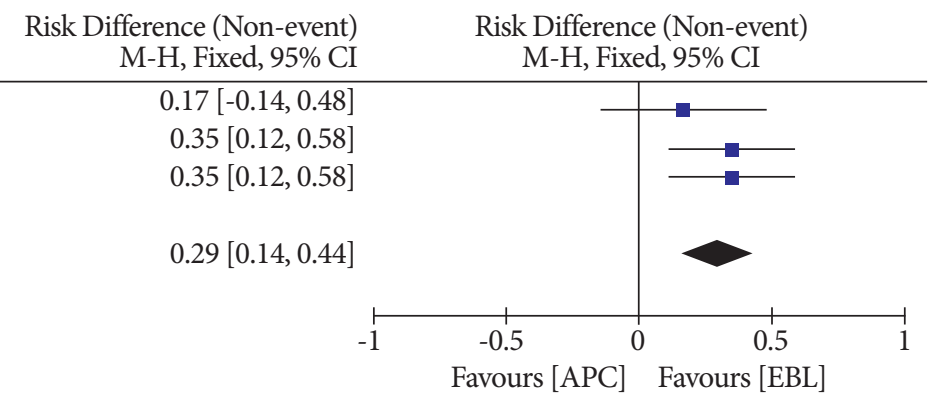

Fig. 2. Endoscopic eradication. APC, argon plasma coagulation; $\mathrm{Cl}$, confidence interval; EBL, endoscopic band ligation; $\mathrm{M}-\mathrm{H}$, Mantel-Haenszel test.

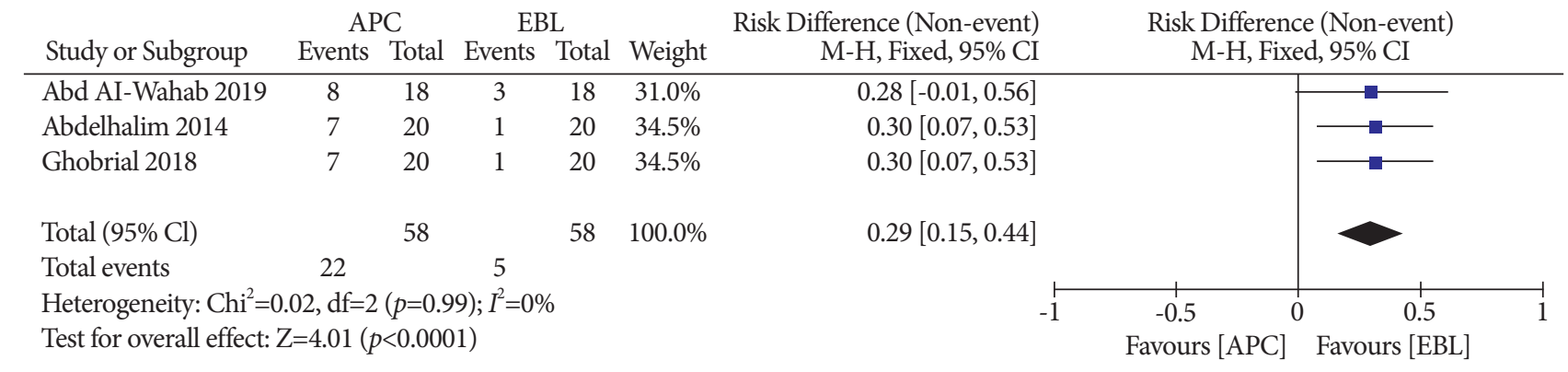

Fig. 3. Recurrence of bleeding. APC, argon plasma coagulation; $\mathrm{Cl}$, confidence interval; $\mathrm{EBL}$, endoscopic band ligation; M-H, Mantel-Haenszel test. 


\section{Transfusion requirement}

In total, 168 patients from three studies were analyzed. ${ }^{37-39}$ The group treated with EBL required fewer transfusions (mean difference $[\mathrm{MD}], 1.49 ; 95 \%$ CI $\left.[0.28,2.71] ; p=0.02 ; I^{2}=96 \%\right)$ (Fig. 4). The GRADE analysis revealed a very low certainty of evidence.

\section{Number of sessions}

In total, 204 patients from four studies were analyzed. ${ }^{37-40}$ The number of sessions required for complete obliteration of the lesions was higher in the APC group (MD, 1.38; 95\% CI $[0.35,2.42] ; p=0.009 ; I^{2}=94 \%$ ) (Fig. 5). The GRADE analysis revealed a very low certainty of evidence.

\section{Mean number of hospitalizations}

In total, 80 patients from two studies were analyzed. ${ }^{37,39}$ The group treated with EBL required fewer hospitalizations than patients in the APC group (MD, 0.29; 95\% CI [0.19, 0.39]; $p<0.00001 ; I^{2}=0 \%$ ) (Fig. 6). The GRADE analysis revealed a moderate certainty of evidence.

\section{Adverse events}

In total, 204 patients in four studies were analyzed. ${ }^{37-40}$ There was no significant difference between them $(\mathrm{RD},-0.20$; 95\% CI $[-0.48,0.07] ; p=0.15 ; I^{2}=91 \%$ ) (Fig. 7). The GRADE analysis revealed a very low certainty of evidence.

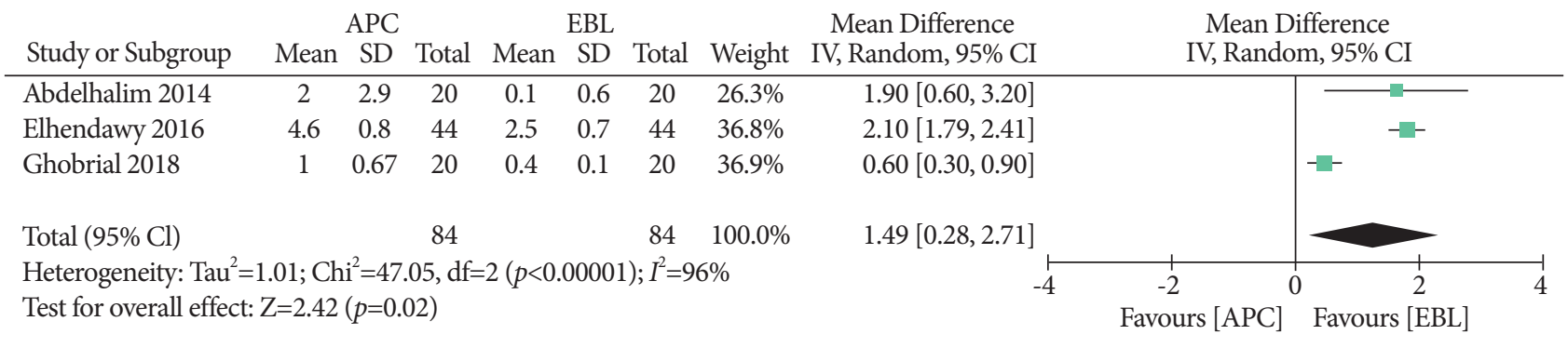

Fig. 4. Transfusion requirement. APC, argon plasma coagulation; $\mathrm{Cl}$, confidence interval; $\mathrm{EBL}$, endoscopic band ligation; IV, inverse variance; SD, standard deviation.

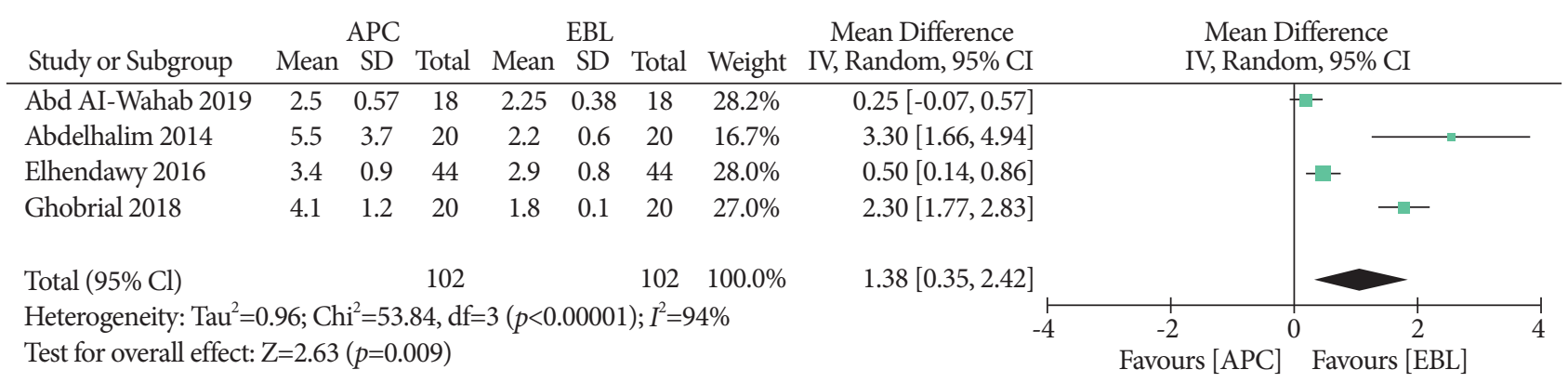

Fig. 5. Number of sessions. APC, argon plasma coagulation; $\mathrm{Cl}$, confidence interval; $\mathrm{EBL}$, endoscopic band ligation; IV, inverse variance; $\mathrm{SD}$, standard deviation.

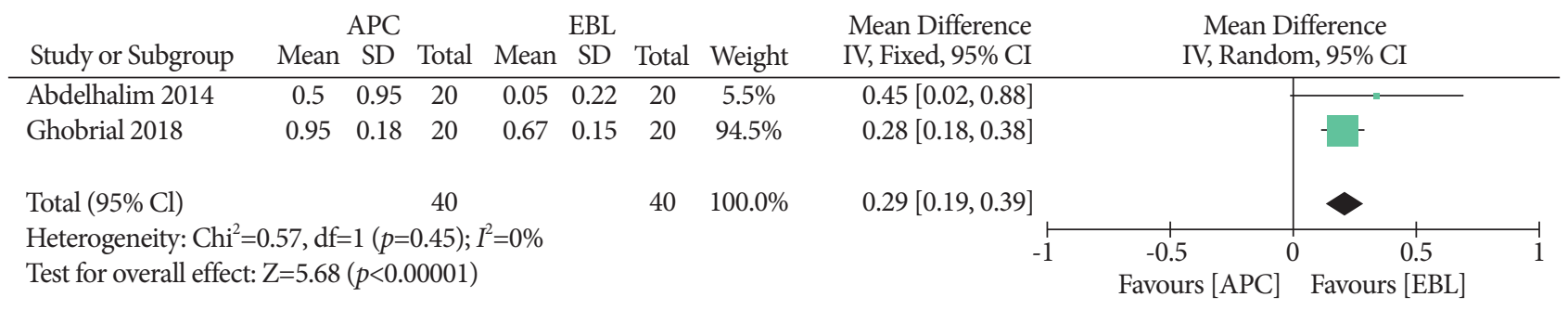

Fig. 6. Number of hospitalizations. APC, argon plasma coagulation; $\mathrm{Cl}$, confidence interval; EBL, endoscopic band ligation; IV, inverse variance; SD, standard deviation. 


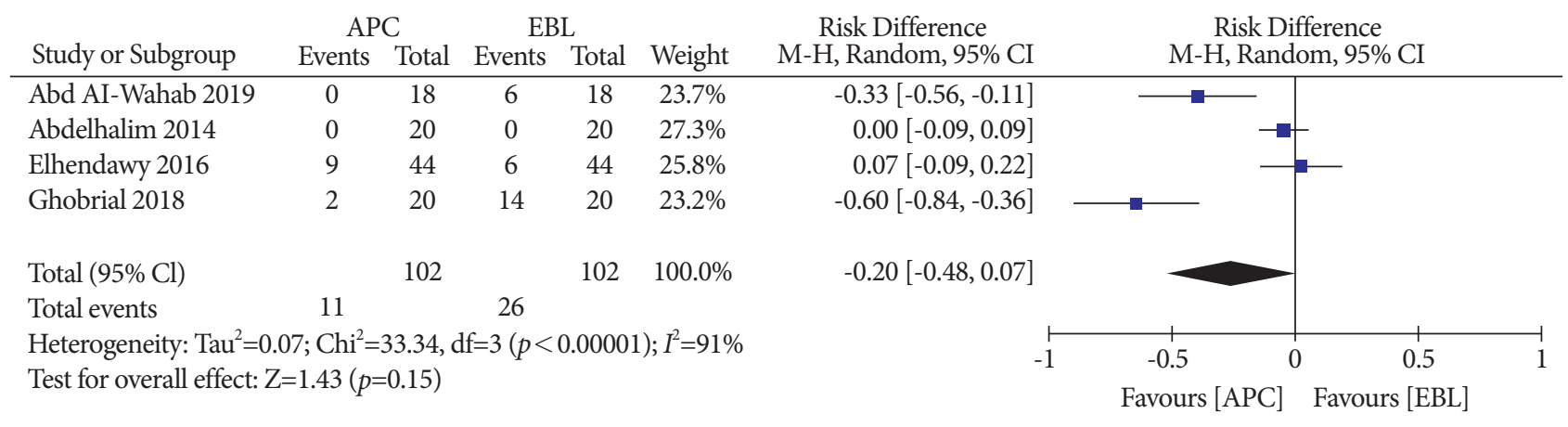

Fig. 7. Adverse events. APC, argon plasma coagulation; $\mathrm{Cl}$, confidence interval; $\mathrm{EBL}$, endoscopic band ligation; $\mathrm{M}-\mathrm{H}$, Mantel-Haenszel test.

\section{DISCUSSION}

GAVE is a common entity that can occur in patients with and without liver cirrhosis and has a different spectrum of treatment and behavior from those of portal hypertensive gastropathy. It has significant morbidity and financial impact as patients are often hospitalized, requiring endoscopic procedures and blood transfusions. However, few high-quality studies have evaluated the optimal treatment modality. The previous meta-analysis ${ }^{41}$ on this subject included only two RCTs, it did not include two relevant outcomes (endoscopic eradication and recurrence of bleeding), and included retrospective studies, which decreased the level of evidence. To our knowledge, this is the first systematic review and meta-analysis that included only randomized controlled trials evaluating both APC and EBL in the treatment of this entity (Level of Evidence 1A).

Our meta-analysis demonstrated that EBL has higher rates of endoscopic eradication, less recurrence of bleeding, and a reduction in transfusion requirements. These results may be explained by the fact that EBL acts on deeper gastric wall layers, leading to thrombosis and ischemia of the mucosa and submucosa, which are subsequently replaced by fibrous tissue (Fig. 8C). Consequently, the blood flow in the vessels that nourish vascular ectasia is interrupted and GAVE is eradicated. In contrast, APC tended to act only on the mucosa (Fig. $8 \mathrm{~B})$. Since GAVE is characterized by dilation of the mucosal and submucosal vessels with focal thrombosis, it is understandable that the deeper action of EBL will promote less recurrence of these lesions. ${ }^{7,8}$

Regarding the number of hospitalizations, we included data from two studies ${ }^{37,39}$ reporting a significantly fewer hospitalizations per patient in the EBL group. Concerning safety, only a few adverse events were reported, such as fever, epigastric pain, abdominal distension, mild bleeding, and vomiting, showing no difference within the procedures. No major adverse events were observed, proving the safety of both methods in line with the recommendations of the American Society for Gastrointestinal Endoscopy Quality Task Force. ${ }^{42}$ One of the included studies ${ }^{40}$ reported the development of hypertrophied polyps in some patients who underwent EBL. However, this is an unusual complication that has already been reported for $\mathrm{APC}^{43-45}$ and RFA. ${ }^{46}$

Despite the efficacy of both techniques in treating GAVE, EBL still presents more advantages. It is more widely available, less time consuming, ${ }^{39}$ and because it requires fewer endoscopic sessions, it is probably associated with lower costs. ${ }^{47}$ However, in some situations, both techniques can be performed complementarily, especially in fibrotic areas related to previously performed banding that are difficult to suction and achieve band deployment.

The exposed results are consistent in patients with chronic liver disease, which represents the etiology of a considerable number of GAVE cases encountered in daily practice. However, other conditions associated with GAVE, such as connective tissue disorders, end-stage renal disease, and bone marrow transplantation, were not evaluated in this study. ${ }^{9,48}$ Since the pathogenesis is not fully understood, it is not possible to confirm whether our results may be extrapolated to other diseases. Nevertheless, two retrospective studies including patients with non-cirrhotic GAVE also reported the superiority of EBL over APC. $^{32,35}$

In this study, we analyzed the two main endoscopic options (EBL and APC) for the treatment of GAVE. There are promising emergent techniques, such as RFA and hybrid-APC, that have not been evaluated in randomized controlled trials; therefore, they were not included in our study. Further studies are needed to compare these techniques with APC and EBL.

The treatment of GAVE is also limited by an incomplete understanding of its pathogenesis. Several hypotheses have been proposed, including mechanical stress caused by abnormal gastric contraction waves and an imbalance of vasoactive and 


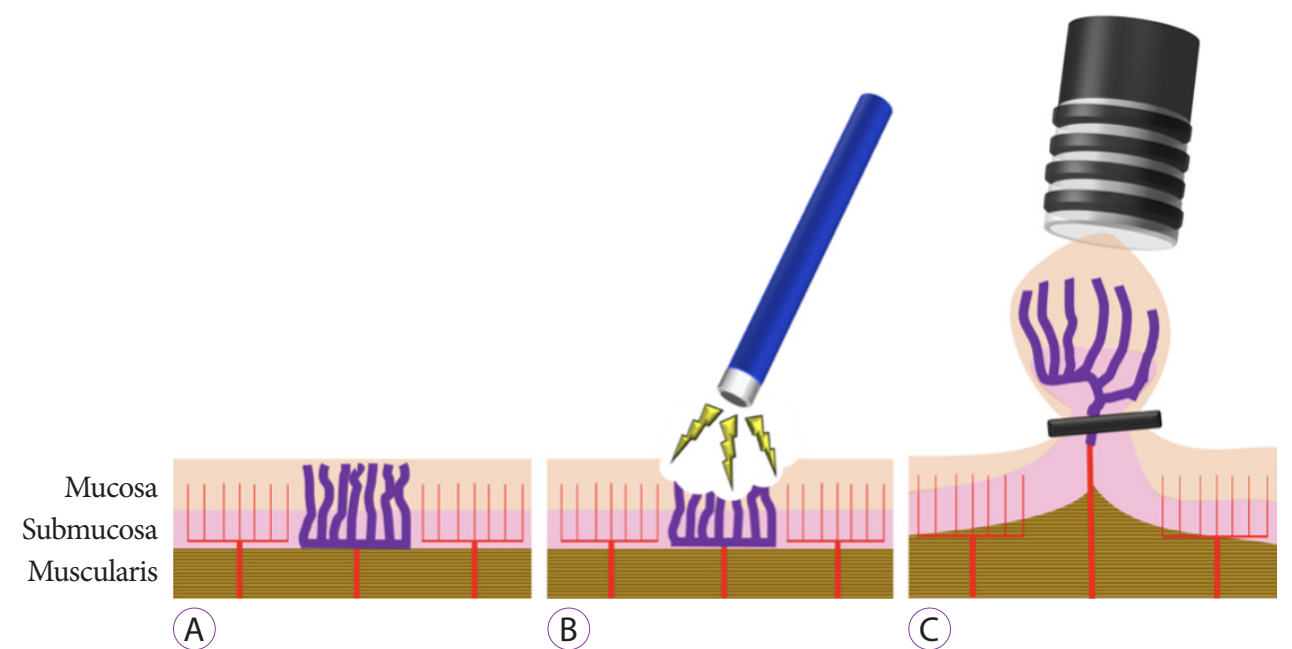

Fig. 8. (A) Mucosa with gastric antral vascular ectasia. (B) Treatment with argon plasma coagulation. (C) Treatment with endoscopic band ligation.

angiogenic mediators. ${ }^{5}$ Treatment of the underlying disease can lead to resolution of GAVE, as reported for patients with cirrhosis treated with liver transplantation and for patients with systemic sclerosis treated with cyclophosphamide. ${ }^{49,50}$ Hence, it is possible that a more accurate understanding of the pathophysiology can lead to better management of this condition.

Our study has several limitations. Few articles were included in the analysis. However, this is because of the small number of RCTs published on this subject. All included studies were conducted in Egypt, which has one of the highest cirrhosis-related death rates in the world. ${ }^{51}$ Nonetheless, our results were consistent with previous observational studies conducted in other countries as well. ${ }^{32,33,35}$ Not all outcomes were evaluated in every trial. Significant heterogeneity was identified among the studies, which might be explained by the following reasons: the severity of the liver disease varied among the studies, as shown in Supplementary Table 4, and different APC settings along with a variable number of endoscopic bands applied in each session. These factors may have influenced the outcomes. One of the included studies was performed in children with liver disease. ${ }^{39}$ However, the results were consistent with those of other studies, probably due to the same pathophysiology in patients with chronic liver disease. Regarding transfusion requirements, none of the studies reported the cutoff to indicate blood transfusions. Nevertheless, all individual studies consistently reported fewer transfusions in patients treated with EBL.

In summary, we performed an extensive systematic and indepth critical evaluation of the best level of evidence for this subject. The available data allow us to recommend EBL as the first treatment option for GAVE. We strongly believe that this can significantly and positively influence the care and management of patients suffering from this condition.

\section{CONCLUSIONS}

Our systematic review and meta-analysis showed that EBL is superior to APC in terms of endoscopic eradication rates, recurrence of bleeding, and transfusion requirements. Similar adverse events were observed for both interventions.

\section{Conflicts of Interest}

Eduardo Guimaraes Hourneaux de Moura received personal fee from Boston Scientific and Olympus, outside the submitted work. The other authors have no potential conflicts of interest.

Funding

None.

\section{Author Contributions}

Conceptualization: Bruno Salomão Hirsch, Igor Braga Ribeiro

Formal analysis: Hirsch BS, Ribeiro IB, Mateus Pereira Funari, Diogo Turiani Hourneaux de Moura, Sergio Eiji Matuguma, Sergio A. Sánchez-Luna, Fabio Catache Mancini, Guilherme Henrique Peixoto de Oliveira, Wanderley Marques Bernardo, Eduardo Guimarães Hourneaux de Moura

Investigation: $\mathrm{BSH}, \mathrm{IBR}$

Methodology: BSH, IBR, WMB, EGHDM

Project administration: BSH, IBR

Supervision: BSH, IBR

Validation: BSH, IBR

Visualization: BSH, IBR, SEM

Writing-original draft: BSH, IBR, MPF, SASL, EGHDM

Writing-review \& editing: BSH, IBR, MPF, SASL, DTHDM, SEM, FCM, GHPDO, WMB, EGHDM 
ORCID

Bruno Salomão Hirsch: Igor Braga Ribeiro: Mateus Pereira Funari: Diogo Turiani Hourneaux de Moura: Sergio Eiji Matuguma: Sergio A. Sánchez-Luna: Fabio Catache Mancini: Guilherme Henrique Peixoto de Oliveir.: Wanderley Marques Bernardo: https://orcid.org/0000-0002-8597-5207 Eduardo Guimarães Hourneaux de Moura: https://orcid.org/0000-0002-8023-3722

\section{REFERENCES}

1. Dulai GS, Jensen DM, Kovacs TOG, Gralnek IM, Jutabha R. Endoscopic treatment outcomes in watermelon stomach patients with and without portal hypertension. Endoscopy 2004;36:68-72.

2. Sebastian S, McLoughlin R, Qasim A, O’Morain CA, Buckley MJ. Endoscopic argon plasma coagulation for the treatment of gastric antral vascular ectasia (watermelon stomach): long-term results. Dig Liver Dis 2004;36:212-217.

3. Gretz JE, Achem SR. The watermelon stomach: clinical presentation, diagnosis, and treatment. Am J Gastroenterol 1998;93:890-895.

4. Ripoll C, Garcia-Tsao G. Management of gastropathy and gastric vascular ectasia in portal hypertension. Clin Liver Dis 2010;14:281-295.

5. Fuccio L, Mussetto A, Laterza L, Eusebi LH, Bazzoli F. Diagnosis and management of gastric antral vascular ectasia. World J Gastrointest Endosc 2013;5:6-13.

6. Hsu W-H, Wang Y-K, Hsieh M-S, et al. Insights into the management of gastric antral vascular ectasia (watermelon stomach). Therap Adv Gastroenterol 2018;11:1756283X17747471.

7. Ito M, Uchida Y, Kamano S, Kawabata H, Nishioka M. Clinical comparisons between two subsets of gastric antral vascular ectasia. Gastrointest Endosc 2001;53:764-770.

8. Thomas A, Koch D, Marsteller W, Lewin D, Reuben A. An analysis of the clinical, laboratory, and histological features of striped, punctate, and nodular gastric antral vascular ectasia. Dig Dis Sci 2018;63:966-973.

9. Selinger CP, Ang YS. Gastric antral vascular ectasia (GAVE): an update on clinical presentation, pathophysiology and treatment. Digestion 2008;77:131-137.

10. Spahr L, Villeneuve JP, Dufresne MP, et al. Gastric antral vascular ectasia in cirrhotic patients: absence of relation with portal hypertension. Gut 1999;44:739-742.

11. Tekola BD, Caldwell S. Approach to the management of portal hypertensive gastropathy and gastric antral vascular ectasia. Clin Liver Dis (Hoboken) 2012;1:163-166.

12. Albitar HAH, Almodallal Y, Papadakis KA, Rajan E, Kamath PS, Iyer $\mathrm{VN}$. Intravenous bevacizumab reduces transfusion requirements and endoscopic interventions in patients with gastric antral vascular ectasia and small bowel angioectasia. Gastroenterology 2020;158:1162-1163.e4.

13. Kamath PS, Lacerda M, Ahlquist DA, McKusick MA, Andrews JC, Nagorney DA. Gastric mucosal responses to intrahepatic portosystemic shunting in patients with cirrhosis. Gastroenterology 2000;118:905-911.

14. Brito HP, Ribeiro IB, de Moura DTH, et al. Video capsule endoscopy vs double-balloon enteroscopy in the diagnosis of small bowel bleeding: A systematic review and meta-analysis. World J Gastrointest Endosc 2018;10:400-421.

15. Ribeiro IB, Rezende DT, Madruga Neto AC, et al. Endoscopic dual therapy for giant peptic ulcer hemorrhage. Endoscopy 2018;50:E316- E317.

16. Lôbo MR de A, Chaves DM, DE Moura DTH, Ribeiro IB, Ikari E, DE Moura EGH. Safety and efficacy of EUS-guided coil plus cyanoacrylate versus conventional cyanoacrylate technique in the treatment of gastric varices: a randomized controlled trial. Arq Gastroenterol 2019;56:99105.

17. Luz GO, Matuguma SE, Madruga Neto AC, et al. A novel technique in the management of refractory variceal bleeding. Endoscopy 2020;52:310-311.

18. de Rezende DT, Brunaldi VO, Bernardo WM, et al. Use of hemostatic powder in treatment of upper gastrointestinal bleeding: a systematic review and meta-analysis. Endosc Int Open 2019;7:E1704-E1713.

19. ASGE technology committee, Parsi MA, Schulman AR, et al. Devices for endoscopic hemostasis of nonvariceal GI bleeding (with videos). VideoGIE 2019;4:285-299.

20. Boltin D, Gingold-Belfer R, Lichtenstein L, Levi Z, Niv Y. Long-term treatment outcome of patients with gastric vascular ectasia treated with argon plasma coagulation. Eur J Gastroenterol Hepatol 2014;26:588-593.

21. Chaves DM, Sakai P, Oliveira CV, Cheng S, Ishioka S. Watermelon stomach: clinical aspects and treatment with argon plasma coagulation. Arq Gastroenterol 2006;43:191-195.

22. Zepeda-Gómez S, Sultanian R, Teshima C, Sandha G, Van Zanten S, Montano-Loza AJ. Gastric antral vascular ectasia: a prospective study of treatment with endoscopic band ligation. Endoscopy 2015;47:538-540.

23. Eccles J, Falk V, Montano-Loza AJ, Zepeda-Gómez S. Long-term follow-up in patients with gastric antral vascular ectasia (GAVE) after treatment with endoscopic band ligation (EBL). Endosc Int Open 2019;7:E1624-E1629.

24. Swanson E, Mahgoub A, MacDonald R, Shaukat A. Medical and endoscopic therapies for angiodysplasia and gastric antral vascular ectasia: a systematic review. Clin Gastroenterol Hepatol 2014;12:571-582.

25. Gross SA, Al-Haddad M, Gill KRS, Schore AN, Wallace MB. Endoscopic mucosal ablation for the treatment of gastric antral vascular ectasia with the HALO90 system: a pilot study. Gastrointest Endosc 2008;67:324-327.

26. Dray X, Repici A, Gonzalez P, et al. Radiofrequency ablation for the treatment of gastric antral vascular ectasia. Endoscopy 2014;46:963-969.

27. Mondragón OH, Valenzuela LL, Valencia JB, Saavedra DE, Velasco GB. Safety and efficacy of hybrid-APC for the treatment of refractory GAVE. In: Endoscopy [Internet]. Leipzig: Georg Thieme Verlag KG; c2018 [updated 2018 Apr 21; cited 2021 Apr 16]. p. ePP069V. Available from: http://www.thieme-connect.de/DOI/DOI?10.1055/s-0038-1637393.

28. Nakamura S, Mitsunaga A, Konishi H, Oi I, Shiratori K, Suzuki S. Longterm follow up of gastric antral vascular ectasia treated by argon plasma coagulation. Dig Endosc 2006;18:128-133.

29. Moher D, Liberati A, Tetzlaff J, Altman DG, PRISMA Group. Preferred reporting items for systematic reviews and meta-analyses: the PRISMA statement. PLoS Med 2009;6:e1000097.

30. Cochrane Handbook for Systematic Reviews of Interventions version 6.0 [Internet]. London (UK); c2019 [updated 2019 July; cited 2021 Apr 16]. Available from: https://training.cochrane.org/handbook

31. Hozo SP, Djulbegovic B, Hozo I. Estimating the mean and variance from the median, range, and the size of a sample. BMC Med Res Methodol 2005;5:13.

32. Wells CD, Harrison ME, Gurudu SR, et al. Treatment of gastric antral vascular ectasia (watermelon stomach) with endoscopic band ligation. Gastrointest Endosc 2008;68:231-236.

33. Sato T, Yamazaki K, Akaike J. Endoscopic band ligation versus argon plasma coagulation for gastric antral vascular ectasia associated with liver diseases. Dig Endosc 2012;24:237-242.

34. Wells CD, Harrison ME, Gurudu SR, et al. Treatment of gastric antral vascular ectasia (watermelon stomach) with endoscopic band ligation. Gastrointest Endosc 2008;68:231-236.

35. Keohane J, Berro W, Harewood GC, Murray FE, Patchett SE. Band ligation of gastric antral vascular ectasia is a safe and effective endoscopic treatment. Dig Endosc 2013;25:392-396.

36. Ghaffar MMA, Maguid HMAE. Endoscopic band ligation versus argon plasma coagulation in management of bleeding from gastric antral vas- 
cular ectasia in patients with portal hypertension. Journal of Medicine in Scientific Research 2019;2:214-219.

37. Abdelhalim H, Mostafa I, Abdelbary MS, Elansary M, Abdo M, Rahim AA. Endoscopic band ligation versus argon plasma coagulation for the treatment of gastric antral vascular ectasia in Egyptian patients with liver cirrhosis. World J Med Sci 2014;10:357-361.

38. Elhendawy M, Mosaad S, Alkhalawany W, et al. Randomized controlled study of endoscopic band ligation and argon plasma coagulation in the treatment of gastric antral and fundal vascular ectasia. United European Gastroenterol J 2016;4:423-428.

39. Ghobrial C, Rabea M, Mohsen N, Eskander A. Gastric antral vascular ectasia in portal hypertensive children: Endoscopic band ligation versus argon plasma coagulation. J Pediatr Surg 2019;54:1691-1695.

40. Amer K, Abd El Wahab N, Ibrahim A. Argon plasma coagulation versus endoscopic band ligation in treatment of gastric antral vascular ectasia in cirrhotic patients in Zagazig University Hospitals. Afro-Egyptian Journal of Infectious and Endemic Diseases 2019;9:176-184.

41. Chalhoub JM, Umar J, Groudan K, Hamadeh N, Desilets DJ, Greeff Y. Endoscopic band ligation compared to thermal therapy for gastric antral vascular ectasia: a systematic review and meta-analysis. United European Gastroenterol J 2020;2050640620975243.

42. Cotton PB, Eisen GM, Aabakken L, et al. A lexicon for endoscopic adverse events: report of an ASGE workshop. Gastrointest Endosc 2010;71:446-454.

43. Farooq FT, Wong RCK, Yang P, Post AB. Gastric outlet obstruction as a complication of argon plasma coagulation for watermelon stomach.
Gastrointest Endosc 2007;65:1090-1092.

44. Izquierdo S, Rey E, Gutiérrez Del Olmo A, Almansa C, Andrés Ramírez Armengol J, Díaz-Rubio M. Polyp as a complication of argon plasma coagulation in watermelon stomach. Endoscopy 2005;37:921.

45. Baudet JS, Salata H, Soler M, et al. Hyperplastic gastric polyps after argon plasma coagulation treatment of gastric antral vascular ectasia (GAVE). Endoscopy 2007;39 Suppl 1:E320.

46. Quevedo R, Moehlen M, Joshi V. Gastric inflammatory polyps as a sequela of radiofrequency ablation for the treatment of gastric antral vascular ectasia: 1006. ACG 2011;106:S375.

47. Tantau M, Crisan D. Is endoscopic band ligation the gold standard for gastric antral vascular ectasia? Endosc Int Open 2019;7:E1630-E1631.

48. Burak KW, Lee SS, Beck PL. Portal hypertensive gastropathy and gastric antral vascular ectasia (GAVE) syndrome. Gut 2001;49:866-872.

49. Vincent C, Pomier-Layrargues G, Dagenais M, et al. Cure of gastric antral vascular ectasia by liver transplantation despite persistent portal hypertension: a clue for pathogenesis. Liver Transpl 2002;8:717-720.

50. Schulz SW, O'Brien M, Maqsood M, Sandorfi N, Del Galdo F, Jimenez SA. Improvement of severe systemic sclerosis-associated gastric antral vascular ectasia following immunosuppressive treatment with intravenous cyclophosphamide. J Rheumatol 2009;36:1653-1656.

51. Sepanlou SG, Safiri S, Bisignano C, et al. The global, regional, and national burden of cirrhosis by cause in 195 countries and territories, 19902017: a systematic analysis for the Global Burden of Disease Study 2017. Lancet Gastroenterol Hepatol 2020;5:245-266. 